\title{
Morphometric changes in the aortic arch with advancing age in fetal to mature thoroughbred horses
}

\author{
Chihiro ENDOH ${ }^{1)}$, Kazuya MATSUDA ${ }^{1)}$, Minoru OKAMOTO ${ }^{1)}$, Nobuo TSUNODA ${ }^{2)}$ \\ and Hiroyuki TANIYAMA ${ }^{1) *}$ \\ 1)Department of Veterinary Pathology, Rakuno Gakuen University, 582 Midori-machi, Bunkyo-dai, Ebetsu, \\ Hokkaido 069-8501, Japan \\ 2)Shadai Corporation, Abira, Hokkaido 059-1432, Japan
}

\section{J. Vet. Med. Sci.}

79(3): 661-669, 2017

doi: 10.1292/jvms.16-0600

Received: 19 November 2016 Accepted: 30 January 2017 Published online in J-STAGE: 11 February 2017

\begin{abstract}
Aortic rupture is a well recognized cause of sudden death in thoroughbred horses. Some microscopic lesions, such as those caused by cystic medial necrosis and medionecrosis, can lead to aortic rupture. However, these microscopic lesions are also observed in normal horses. On the other hand, a previous study of aortic rupture suggested that underlying elastin and collagen deposition disorders might be associated with aortic rupture. Therefore, the purpose of this study was to compare the structural components of the tunica media of the aortic arch, which is composed of elastin, collagen, smooth muscle cells and mucopolysaccharides (MPS), in fetal to mature thoroughbred horses. The percentage area of elastin was greatest in the young horses and subsequently decreased with aging. The percentage area of collagen increased with aging, and the elderly horses (aged $\geq 20$ ) exhibited significantly higher percentage areas of collagen than the young horses. The percentage area of smooth muscle cells did not change with age. The percentage area of MPS was inversely proportional to the percentage area of elastin. The fetuses exhibited a markedly larger percentage area of MPS than the mature horses. We concluded that the medial changes seen in the aortic arch, which included a reduction in the amount of elastin and increases in the amounts of collagen and MPS, were age-related variations.
\end{abstract}

KEY WORDS: aorta, aortic arch, equine, histopathology, morphometry

In horses, rupturing of the aorta is a well recognized, but uncommon condition. It mainly affects elderly horses [1,9] and can lead to sudden death [3]. Histopathologically, aortic lesions, including cystic medial necrosis, elastin fragmentation and medionecrosis of the aortic tunica media, might contribute to aortic rupturing [1,9]. While such lesions have been evaluated using medial grading systems based on their extent and localization $[5,18,23]$, the relationship between these lesions and aortic rupturing remains unclear $[14,19,21]$.

On the other hand, recent studies have analyzed the morphometric properties of the aorta in horses, including the proportions of elastin, collagen and smooth muscle cells (SMC) $[15,16]$. However, they did not examine horses with a broad age range. In the present study, histopathological and morphometric analyses of the tunica media of the aortic arch were performed in 90 horses ranging in age from 97 days (embryonic horses) to 29 years old.

\section{MATERIALS AND METHODS}

\section{Animals}

Ninety thoroughbred horses ranging in age from 97 days to 29 years old were included in the present study (Table 1). Macroscopic and microscopic examinations were performed in 90 and 77 of these animals, respectively. All of the horses underwent postmortem examinations at Rakuno Gakuen University after being euthanized or suffering spontaneous death (mainly due to locomotive or alimentary disorders). Horses with cardiovascular disorders were excluded. The investigated animals were divided into 7 groups (Table 1). Group 1 was comprised of fetuses, group 2 was comprised of newborns-5-month-old horses, group 3 was comprised of 6-11-month-old horses, group 4 was comprised of 1-2-year-old horses, group 5 was comprised of 3-9-year-old horses, group 6 was comprised of 10-19-year-old horses, and group 7 was comprised of horses aged over 20 years.

*Correspondence to: Taniyama, H., Department of Veterinary Pathology, Rakuno Gakuen University, 582 Bunkyodai-Midorimachi, Ebetsu, Hokkaido 0698501, Japan. e-mail: taniyama@rakuno.ac.jp

(C2017 The Japanese Society of Veterinary Science

This is an open-access article distributed under the terms of the Creative Commons Attribution Non-Commercial No Derivatives (by-ncnd) License. (CC-BY-NC-ND 4.0: https://creativecommons.org/licenses/by-nc-nd/4.0/) 
Table 1. Numbers of subjects used in the gross and histological studies

\begin{tabular}{clcc}
\hline Group & Age & Gross study & Histological study \\
\hline 1 & fetuses & 19 & 18 \\
2 & $0-5 \mathrm{~m}^{\mathrm{a})}$ & 23 & 16 \\
3 & $6-11 \mathrm{~m}$ & 10 & 10 \\
4 & $1-2 \mathrm{y}^{\mathrm{b})}$ & 9 & 9 \\
5 & $3-9 \mathrm{y}$ & 9 & 7 \\
6 & $10-19 \mathrm{y}$ & 13 & 11 \\
7 & $20-\mathrm{y}$ & 7 & 6 \\
\hline Total & & 90 & 77 \\
\hline
\end{tabular}

a) m: Month-old. b) y: Year-old.

\section{Tissue samples}

In all horses, a section of the aortic arch extending from the brachiocephalic trunk to the first cranial artery; i.e., the dorsal intercostal artery or the bronchoesophageal artery, and the surrounding connective tissue were removed. Samples were collected from three sections of the aorta: proximal samples were collected from the region between the brachiocephalic trunk and the ligamentum arteriosum, "middle" samples were obtained from the region starting $2 \mathrm{~cm}$ caudal from the ligamentum arteriosum, and distal samples were acquired from the region between the middle sample and the dorsal intercostal artery or bronchoesophageal artery.

\section{Gross examinations}

Macroscopically, the luminal diameter $(\mathrm{cm})$ and thickness $(\mathrm{mm})$ of cross-sections of the fixed aorta were measured in 90 horses.

\section{Histological examinations}

After the macroscopic examinations, dorsal aortic samples from 77 horses were fixed in $10 \%$ formalin and used for histopathological examinations. The samples were processed routinely and embedded in paraffin wax. The resultant sections (4 $\mu \mathrm{m})$ were stained with hematoxylin and eosin (HE). In addition, Victoria blue (VB), Sirius red (SR), periodic acid Schiff (PAS) and Alcian blue (pH2.5) were used to stain elastic lamellae, collagen fibers and mucopolysaccharides (MPS). Contiguous sections from the same field were used for the histopathological, immunohistochemical and statistical analyses.

Fixed sections from the middle samples were washed and placed in Holt's hypertonic gum sucrose to produce frozen sections. The samples were embedded in Tissue Mount (Chiba Medical, Saitama, Japan), before being frozen and stored at $-80^{\circ} \mathrm{C}$. The frozen sections were stained with Sudan black or oil red O to identify neutral fat. Frozen sections of normal livers collected from 2-21-year-old horses (the same horses from which the aortic arch specimens were obtained) were used as a positive control. Cystic medial necrosis in the tunica media was scored from 0 (no) to 3 (severe) according to the system described by Halushka et al. [2]. Medionecrosis (SMC nuclei loss) in the tunica media was scored from 0 (absent) to 3 (extensive) according to the system described by Halushka et al. [2].

\section{Immunohistochemical examinations}

Immunohistochemical examinations of paraffin-embedded sections were performed using the avidin-biotin-peroxidase complex (ABC) method (VECTASTAIN Elite ABC kit; Vector Laboratories, Burlingame, CA, U.S.A.). The primary antibody was a mouse monoclonal antibody against human alpha-smooth muscle actin (SMA) (clone 1A4, 1 in 100 dilution; Dako, Glostrup, Denmark). To remove endogenous peroxidase, the sections were immersed in $0.5 \%$ periodic acid solution at room temperature for 20 min. The sections were then incubated in primary antibody solution at $4^{\circ} \mathrm{C}$ for $14 \mathrm{hr}$. After being washed with phosphate-buffered saline, the sections were incubated in secondary antibody solution at room temperature for $30 \mathrm{~min}$. After being incubated, the sections were reacted with $\mathrm{ABC}$ solution at room temperature for $30 \mathrm{~min}$. Visualization was accomplished using 3'3-diaminobenzedine solution. The sections were counterstained with Mayer's hematoxylin. Sections without the primary antibody were subjected to the same procedures as a negative control.

\section{Imaging analysis}

The thickness of the aortic tunica media was measured in 70 horses by examining sections in which elastin had been stained at magnifications of $\times 40$ and $\times 100$. The percentage thickness of the tunica media was calculated by dividing the thickness of the tunica media by the macroscopic thickness of the whole aorta. The percentage areas of elastin, collagen and SMC were determined based on image analysis. The results were used to calculate the percentage area of MPS. The measurements were obtained with a microscope by examining six randomly selected areas of the tunica media per slide at a magnification of $\times 400$ using a Sony DXC-S500 digital camera (Sony Corporation, Tokyo, Japan). Six areas were selected for each of the three sections of the aorta. Three of the six areas contained the inner third of the tunica media, and the other three areas contained the outer third of the tunica media. The areas of elastin, collagen and SMC were measured as percentages of the total area and were calculated using image analysis software (ImageJ, U. S. National Institutes of Health, Bethesda, MD, U.S.A.) [11]. The percentage area of MPS tissue was 


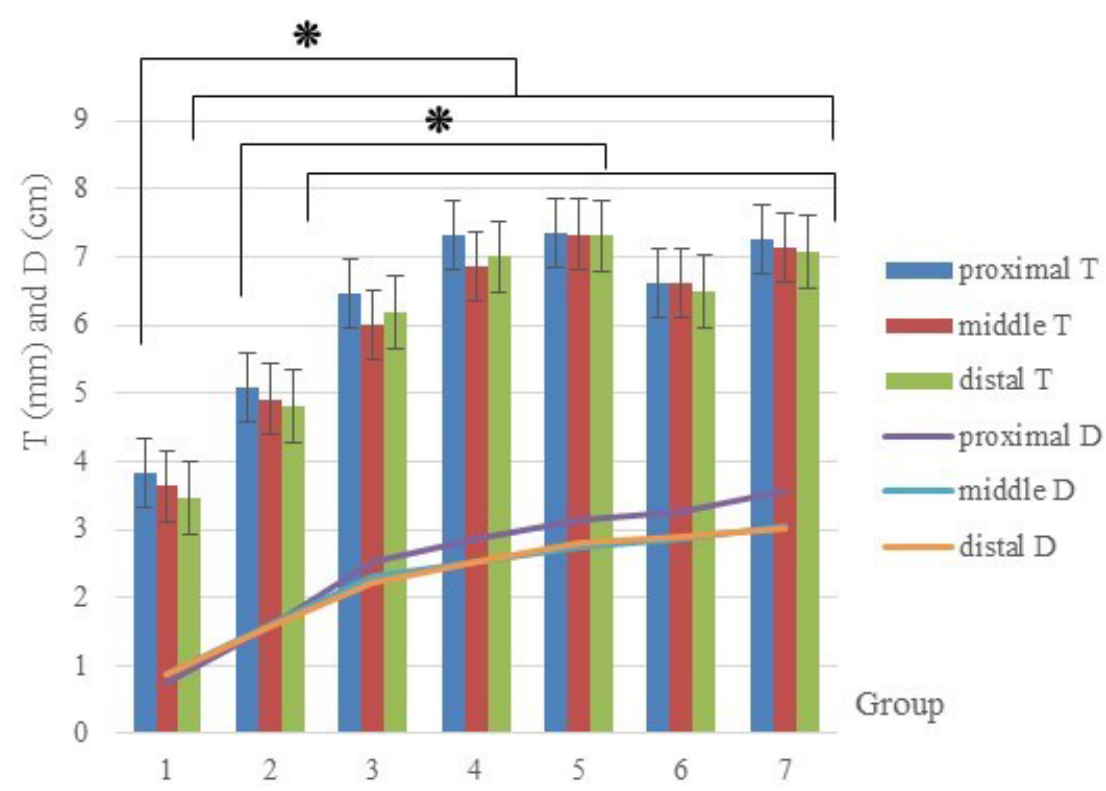

Fig. 1. Thickness (T) and luminal diameter (D) of the aortic arch. The bar graph shows the thickness (mm) of three sections of the aorta. The line graph indicates the luminal diameter $(\mathrm{cm})$ of the same three sections of the aorta. The $\mathrm{T}$ and $\mathrm{D}$ of each section of the aorta increased with age. $* P<0.05$.

calculated by subtracting the percentage areas of the three components described above from the total area. A semi-quantitative evaluation of the actual area of each component was conducted based on the percentages of these four components and the thickness of the tunica media.

\section{Statistical analysis}

Statistical analyses of the 7 groups and comparisons between the proximal and distal sections were performed using the TukeyKramer test and F-test. $P$-values of $<0.05$ were considered to indicate statistical significance.

\section{RESULTS}

\section{Gross findings}

The luminal diameter and thickness of the aortic arch increased with age in all three examined sections (Fig. 1). The luminal diameter and thickness of the aortic arch differed significantly between group 1 and groups $2-7$, and between group 2 and groups 3-7. However, the luminal diameter and thickness of the aortic arch did not differ significantly among the three sections (Fig. 1).

\section{Histological findings}

Thickness of the tunica intima and media (Fig. 2)

All percentages represent mean values for the relevant group.

In group 1 , the tunica intima and media were $32 \mu \mathrm{m}$ and $3,843 \mu \mathrm{m}$ thick, respectively. The percentage thickness of the tunica media was $99.8 \%$.

In group 2, the tunica intima and media were $49 \mu \mathrm{m}$ and 5,216 $\mu \mathrm{m}$ thick, respectively. The percentage thickness of the tunica media was $99.1 \%$.

In group 3, the tunica intima and media were $64 \mu \mathrm{m}$ and $6,536 \mu \mathrm{m}$ thick, respectively. The percentage thickness of the tunica media was $99.02 \%$.

In group 4, the tunica intima and media were $61 \mu \mathrm{m}$ and 7,296 $\mu \mathrm{m}$ thick, respectively. The percentage thickness of the tunica media was $99.2 \%$.

In group 5, the tunica intima and media were $55 \mu \mathrm{m}$ and 7,409 $\mu \mathrm{m}$ thick, respectively. The percentage thickness of the tunica media was $99.3 \%$.

In group 6 , the tunica intima and media were $62 \mu \mathrm{m}$ and $6,620 \mu \mathrm{m}$ thick, respectively. The percentage thickness of the tunica media was $99.1 \%$.

In group 7, the tunica intima and media were $62 \mu \mathrm{m}$ and 7,250 $\mu \mathrm{m}$ thick, respectively.

The mean percentage thickness of the tunica media was $99.14 \%$. The tunica media accounted for most of the aortic wall (at least 98.7\%; mean: 99.1\%). 


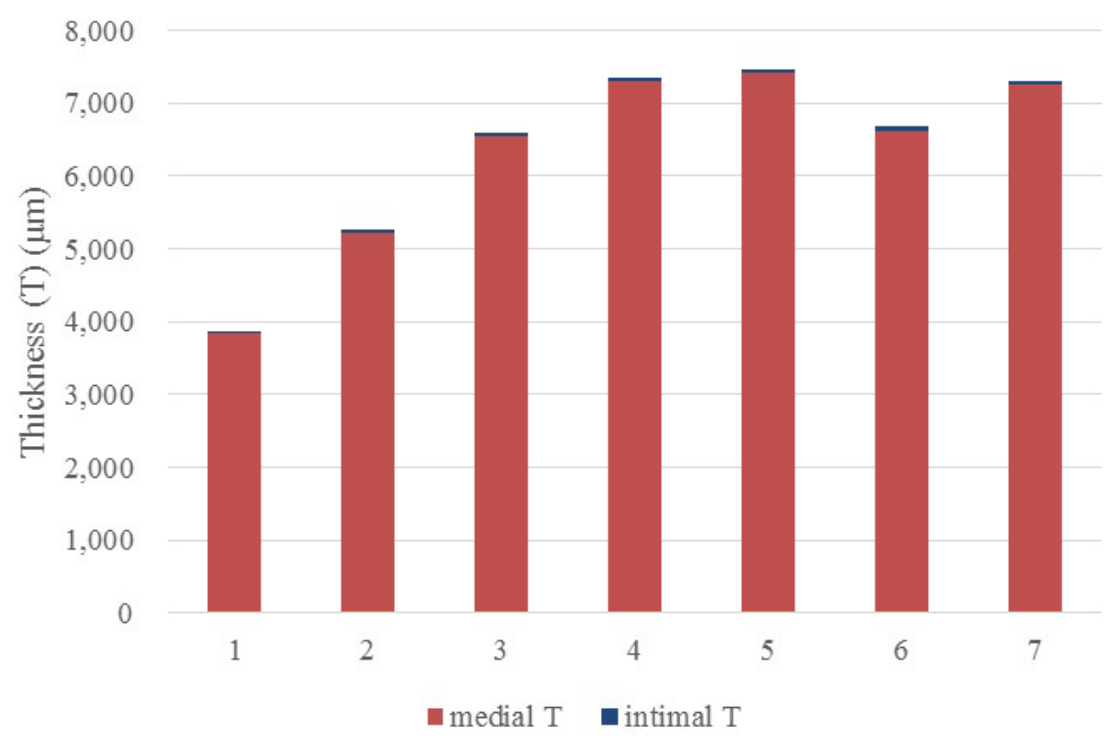

Fig. 2. Thickness of the intima and tunica media of the aortic arch. The tunica media accounted for most of the aortic arch.

\section{Histopathological morphometry}

All percentages represent mean values for the relevant group (Figs. 3-8).

Group 1 exhibited the following specific percentage volumetric values: elastin, proximal: 12\%, distal: 14\%; collagen, proximal: 7\%, distal: $12 \%$; SMC, proximal: $21 \%$, distal: $24 \%$; and MPS, proximal: $60 \%$, distal: $51 \%$.

Group 2 displayed the following specific percentage volumetric values: elastin, proximal: $24 \%$, distal: $25 \%$; collagen, proximal: $12 \%$, distal: $12 \%$; SMC, proximal: $24 \%$, distal: $27 \%$; and MPS, proximal: $40 \%$, distal: $36 \%$.

Group 3 demonstrated the following specific percentage volumetric values: elastin, proximal: 29\%, distal: 32\%; collagen, proximal: $14 \%$, distal: $16 \%$; SMC, proximal: $22 \%$, distal: $27 \%$; and MPS, proximal: $35 \%$, distal: $25 \%$.

Group 4 displayed the following specific percentage volumetric values: elastin, proximal: $23 \%$, distal: 27\%; collagen, proximal: 13\%, distal: $13 \%$; SMC, proximal: $25 \%$, distal: $30 \%$; and MPS, proximal: $39 \%$, distal: $30 \%$.

Group 5 exhibited the following specific percentage volumetric values: elastin, proximal: $23 \%$, distal: $22 \%$; collagen, proximal: 16\%, distal: $14 \%$; SMC, proximal: $26 \%$, distal: $34 \%$; and MPS, proximal: $35 \%$, distal: $30 \%$.

Group 6 demonstrated the following specific percentage volumetric values: elastin, proximal: 17\%, distal: 21\%; collagen, proximal: $17 \%$, distal: $17 \%$; SMC, proximal: $25 \%$, distal: $28 \%$; and MPS, proximal: $41 \%$, distal: $34 \%$.

Group 7 displayed the following specific percentage volumetric values: elastin, proximal: 15\%, distal: 17\%; collagen, proximal: 29\%, distal: $20 \%$; SMC, proximal: $23 \%$, distal: $32 \%$; and MPS, proximal: $33 \%$, distal: $31 \%$.

\section{Statistical analysis}

Statistical comparisons among the 7 groups or between the proximal and distal samples (Figs. 4-6 and Table 2) revealed several significant differences $(P<0.05)$. In the proximal region, the percentage area of elastin was significantly lower in group 1 than in groups $2,3,4,5$ and 6 . In addition, it was significantly higher in group 2 than in groups 6 and 7. Similarly, it was significantly higher in group 3 than in groups 2, 4, 5, 6 and 7, and it was significantly higher in group 4 than in groups 6 and 7. In the distal region, the percentage area of elastin differed significantly between group 1 and groups $2-5$, and between groups $2-4$ and groups $6-7$.The percentage area of collagen in the proximal and distal regions was significantly lower in group 1 than in groups 3 and 6 , whereas it was higher in group 7 than in groups 1,2, 4 and 5. In the proximal region, group 7 exhibited a significantly higher percentage area of collagen than groups 3 and 6.The percentage area of SMC did not differ significantly among the 7 groups. Only the percentage area of elastin in group 3 differed significantly between the proximal and distal regions.

\section{Histopathological lesions}

Histopathologically, some aortic lesions, including lesions exhibiting cystic medial necrosis (Fig. 9), elastin fragmentation, medionecrosis, focal calcification or ossification, were incidentally observed. The cystic medial necrosis lesions caused the accumulation of acidic MPS, which were strongly stained with Alcian blue and negatively stained with PAS. Cystic medial necrosis was commonly observed in all groups. In group 2, some small cystic lesions were seen, and the number and size of the lesions increased with age. These lesions were commonly found in the internal media, and exophytic growth was noted in the tunica media. The mean score for cystic medial necrosis increased with advancing age (group 1: 0.4; group 2: 0.64; group 3: 0.7; group 4: 1.1; group 5: 1.43; group 6: 1.38; and group 7: 2.8). The cystic medial necrosis score differed significantly between group 7 and the other groups, as well as between groups 1-3 and groups 5-6. Elastin fragmentation was observed in all horses according 


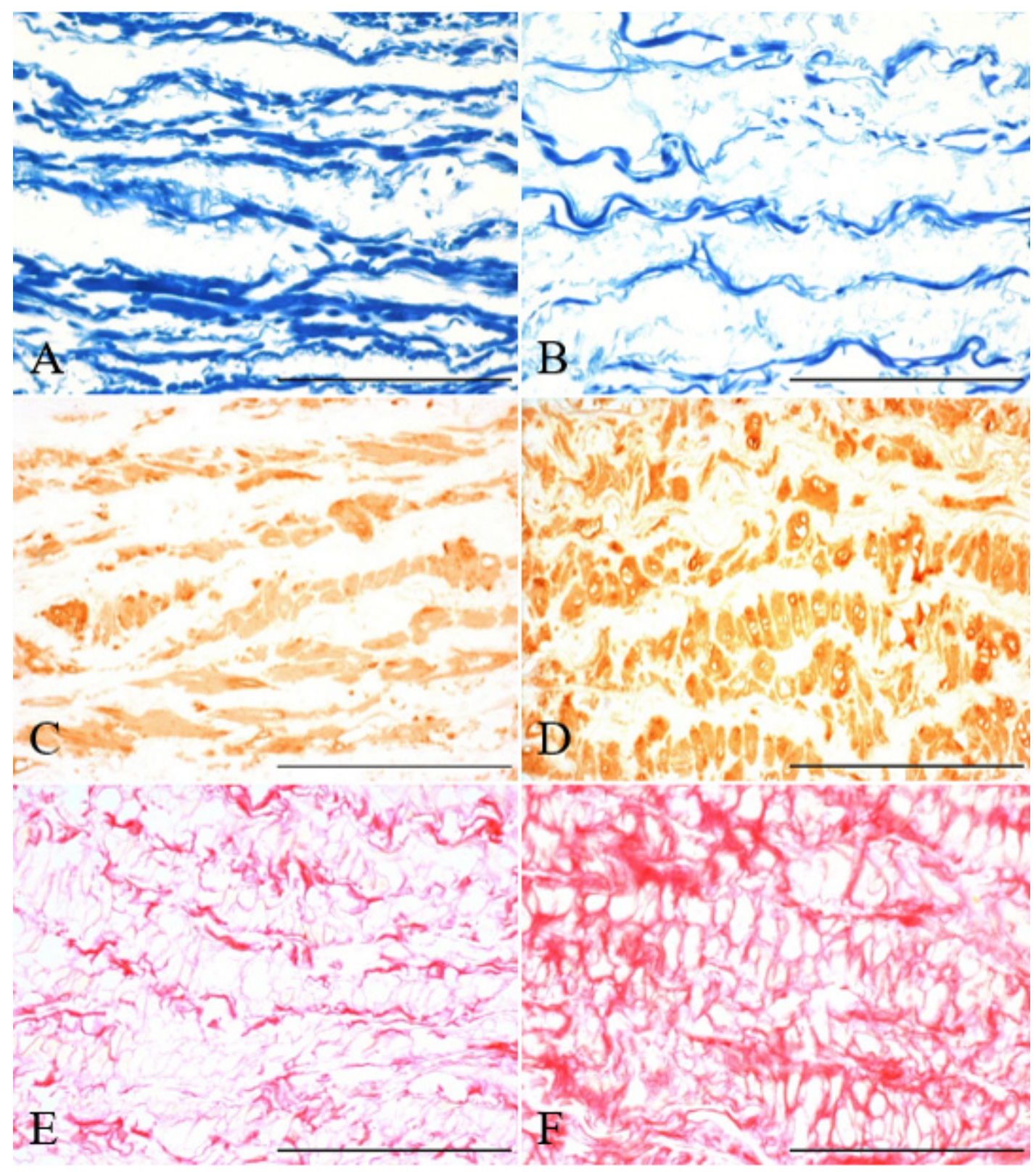

Fig. 3. Histological findings obtained with various stains. An 11-month-old horse: the findings obtained with VB (image A), SMA antibody (image C) and SR (image E). A 25-year-old horse: the findings obtained with VB (image B), SMA antibody (image D) and SR (image F). Bar, $100 \mu \mathrm{m}$

to the system described by Schlatmann et al. [18]. One or two elastin lamellae per unit [2] were detected in groups 1, 6 and 7, and approximately $2-4$ elastin lamellae per unit were seen in groups $2-5$. Medionecrosis was observed in the horses aged $\geq 9$ years. Medionecrosis was commonly found in the middle region and was detected at one or two sites per slide. The mean score for medionecrosis did not differ significantly among the 7 groups (group 1: 0; group 2: 0.1; group 3: 0.2 ; group 4: 0.1 ; group 5: 0.7 ; group 6: 0.9; and group 7: 0.6). Focal calcification involving lamellar units was observed in the horses aged $\geq 17$ years. Ossification was seen in a 29-year-old stallion. This lesion was more severe in the proximal region than in the other two regions. In this study, the cystic medial necrosis, elastin fragmentation and calcification lesions did not display any particular predisposition towards any of the three examined regions of the aorta. In addition, the samples containing these lesions were negatively stained with Sudan black and oil red $\mathrm{O}$.

\section{DISCUSSION}

\section{Gross examination}

The luminal diameter and thickness of all of the examined sections of the aorta increased with age. This suggests that 


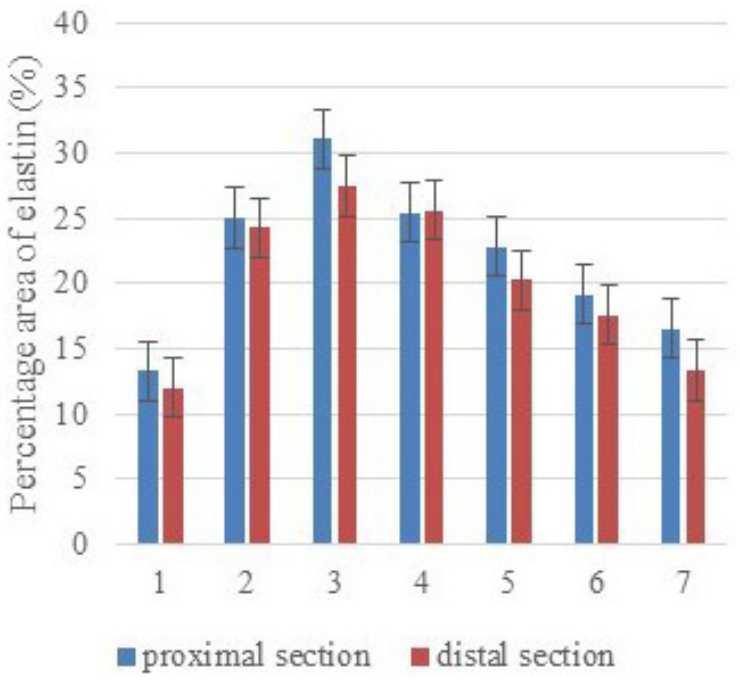

Fig. 4. The percentage area of elastin (VB-positive tissue) in the aortic tunica media. The percentage area of elastin increased from groups 1 to 3 , and then, it decreased with age. Refer to Table 2 for information regarding the significance of the intergroup differences.

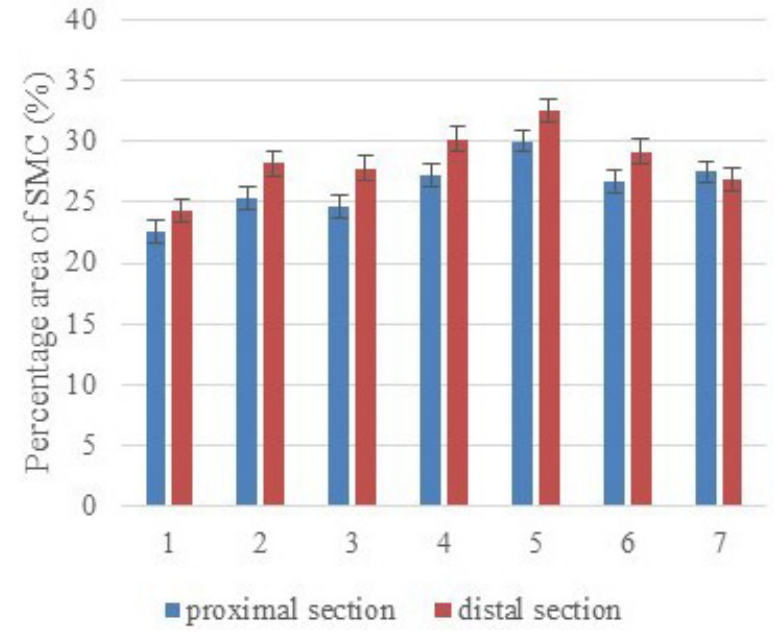

Fig. 6. The percentage area of SMC (SMA-positive cells) in the aortic tunica media. The percentage area of SMC did not change with age.

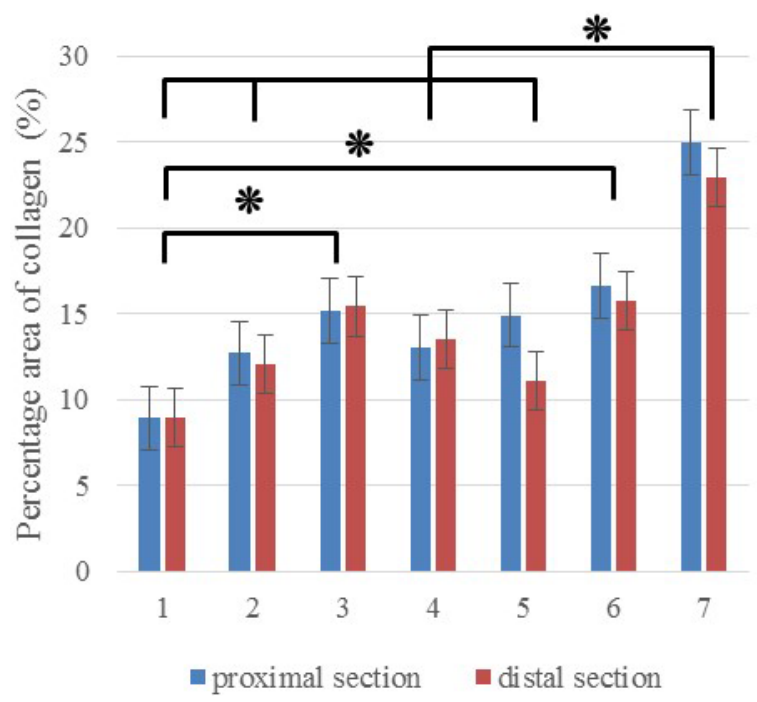

Fig. 5. The percentage area of collagen (SR-positive tissue) in the aortic tunica media. The percentage area of collagen increased with aging. $* P<0.05$.

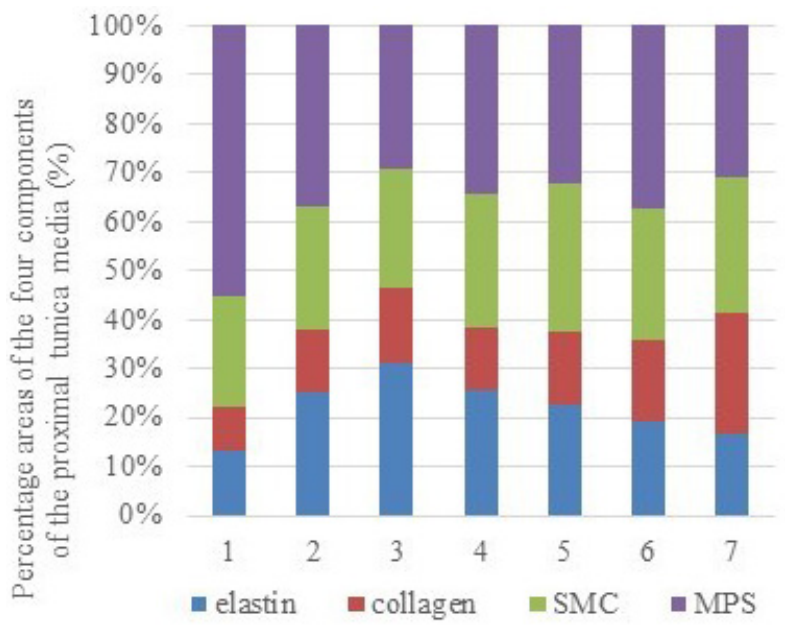

Fig. 7. Percentage areas of the four components (VB-, SR-, SMA- and MPS-positive tissues) of the tunica media in the proximal region. The sum total was $100 \%$.

thoroughbred horses exhibit a similar tendency to humans with regard to the age-related changes in their aortas $[4,6]$.

\section{Histological findings}

Proportional thickness of the tunica media

Histopathologically, the wall of the aortic arch was predominantly composed of the tunica media. No marked increases in intimal thickness were detected in the present study. This result differs from findings obtained in humans [22] and dogs [13], in which the thickness of the intima increased with age. Therefore, the risk of aortic rupture in thoroughbred horses might be more strongly related to medial lesions than intimal lesions.

\section{Histopathological morphometry and statistical analysis}

Histopathologically, the aortic media did not exhibit lipid or cholesterol crystal deposition, which have been reported previously [5]. For this reason, we classified the structural components of the aortic media into four categories, elastin, collagen, SMC and MPS. The percentage area of elastin was at least $10 \%$ in all age groups. Similarly, the percentage area of SMC was at least $25 \%$ 


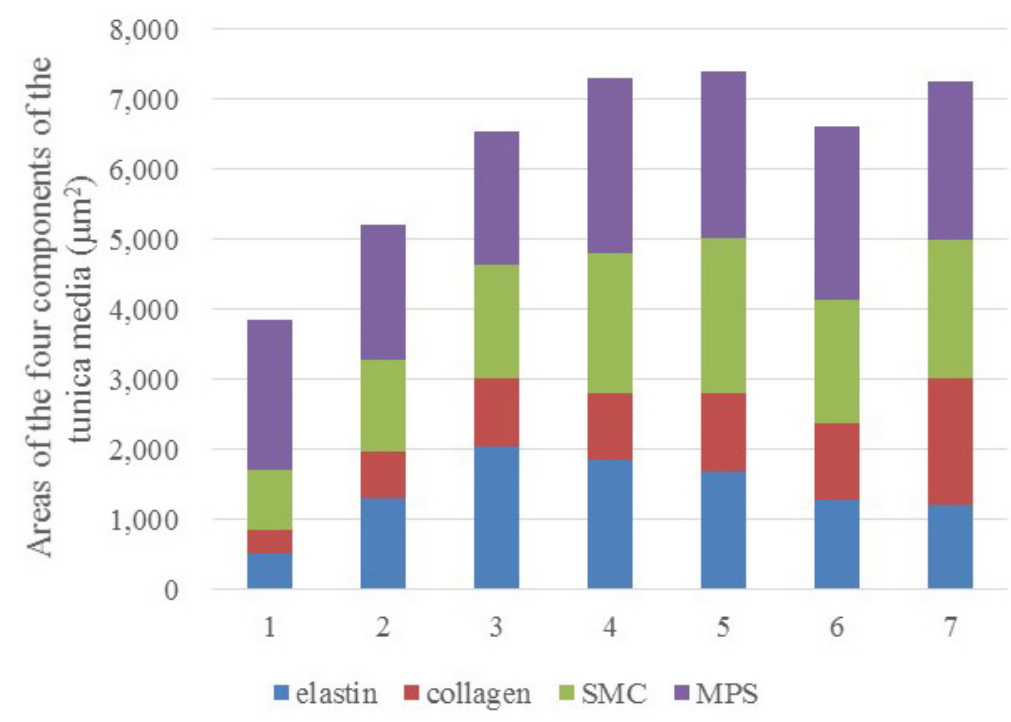

Table 2. The significance of the intergroup differences in the percentage area of elastin

\begin{tabular}{ccccc}
\hline & 1 & 2 & 3 & 4 \\
\hline 2 & $* * a)$ & & & \\
3 & $* *$ & $* b)$ & & \\
4 & $* *$ & & $*$ & \\
5 & $* *$ & & $*$ & \\
6 & $*$ & $* *$ & $* *$ & $* *$ \\
7 & & $* *$ & $* *$ & $* *$ \\
\hline
\end{tabular}

a)**: Both the proximal and distal sections displayed significant age-related differences. $\mathrm{b})^{*}$ : Only the proximal section exhibited significant age-related differences $(P<0.05)$.

Fig. 8. Areas of the four components of the tunica media in the proximal region. This graph is based on the results shown in Figs. 2 and 7.

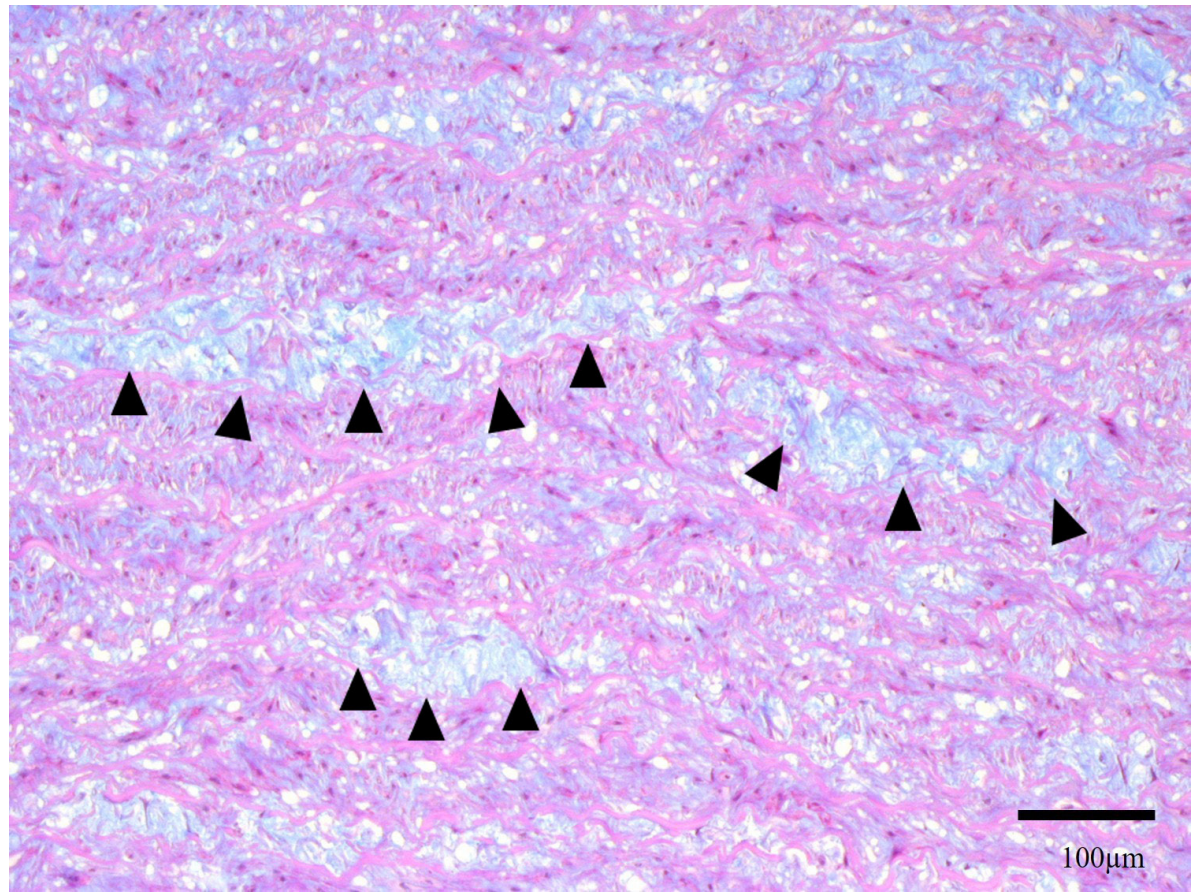

Fig. 9. The internal media in the proximal region. Cystic medial necrosis resulted in the accumulation of acidic MPS, which were strongly stained with Alcian blue (arrowheads). The image shows moderate grade (score 2) cystic medial necrosis in an 18-month-old (1.5-year-old) horse. The section was stained with PAS and Alcian blue (pH2.5).

in all age groups. On the other hand, the percentage areas of elastin and SMC were significantly lower and significantly higher, respectively, in the thoracic aortas of Friesian horses that suffered aortic rupture than in the thoracic aortas of control Friesian horses [15]. These findings suggest that specific proportions of elastin and SMC are important for aortic stability. The percentage area of elastin was lowest in group 1. The percentage area of elastin increased from group 1 to group 3 and decreased from groups 3 to group 7. Elastin is only synthesized during the early stages of life and progressively deteriorates with aging [8, 17]. In thoroughbred horses, elastin is synthesized in the first year of life, and the amount of elastin progressively decreases with advancing age. The percentage area of collagen was lowest in group 1. The percentage area of collagen increased with advancing age and peaked in group 7. Increasing collagen density might be associated with hypertension [12] or arterial rupturing/aneurysms 
[20]. The blood pressure values of thoroughbred horses are generally higher than those of other breeds of horse [7]. In our study, collagen deposition was considered to be an aging-related physiological reaction. The percentage area of SMC was lowest in group 1 and slowly increased with advancing age. Nevertheless, the change in the percentage area of SMC was the smallest such change seen among the four examined structural components. Furthermore, the percentage area of SMC did not differ significantly among the 7 groups. On the other hand, the proportion of the aortic media accounted for by SMC (Fig. 8) increased with age. This indicates that SMC grow with age. In addition, SMC hypertrophy was detected during histopathological examinations. The percentage area of MPS was largest in group 1. The percentage area of MPS was inversely proportional to the percentage area of elastin. This study is the first to examine the age-related changes in the percentage area of MPS in the equine aortic media. The age-related changes in the percentage area of MPS observed in this study were similar to the changes in the human interstitial ratio described in a study of newborns and children [10].

\section{Histopathological lesions}

Medionecrosis was only observed in aged horses. Some previous reports have suggested that medionecrosis might predispose the affected vessels to rupture [14, 21]. In Friesian and Dutch halfbreed horses, aortic rupturing typically occurs near the ligamentum arteriosum, where medionecrosis is most commonly found [21]. In thoroughbred horses, such rupturing commonly occurs near the junction with the heart [3]. In thoroughbred stallions that had suffered aortic rupture, medionecrosis was found underneath the rupture sites. In addition, the aortic rupturing seen in these cases was considered to have been caused by marked increases in blood pressure during breeding $[14,15]$. In our study, medionecrosis was more commonly found in the middle sections near the ligamentum arteriosum than the proximal sections. Therefore, the findings of this study suggest that in thoroughbred horses, rupturing of the aorta is not only caused by medionecrosis. MPS deposition is generally reported to occur in cystic medial necrosis lesions. Cystic medial necrosis has been suggested to be an underlying cause of aortic rupturing [9, 14, 19]; however, other studies have indicated that it is related to physiological activity $[13,18]$. In our study, cystic medial necrosis was first found in a $234-$ dayold (embryonic) horse. These lesions increased in number, size and score with aging. In young horses, the cystic medial necrosis was confined to the internal media, whereas in the elderly horses, cystic lesions were found from the internal to middle media. Our findings indicate that the amount of MPS does not affect the risk of aortic rupturing because the largest amount of MPS was found in group 1. Therefore, it is suggested that the localization of MPS (focal deposition) is more important than the quantity of MPS in terms of the risk of aortic rupture. Thus, cystic medial necrosis might be an underlying cause of aortic rupturing, but such rupturing might be caused by multiple defects.

In conclusion, our study revealed that the medial histological components of the aortic arch undergo changes, including a reduction in the amount of elastin and increases in the amounts of collagen and MPS, with advancing age in thoroughbred horses. These changes are similar to the changes described in a previous report [15], which detected a reduction in the amount of elastin and an increase in the amount of collagen. However, none of the horses in the latter study suffered aortic rupture. Therefore, morphometric changes occur in the aortic media as part of the normal aging process in thoroughbred horses. As the percentage area of each component of the aorta varies according to age, it is necessary to use horses of the same age when performing comparisons of the tunica media in the aortic arch.

\section{REFERENCES}

1. Briceño, A. M., Mendez, A., Brewer, K., Hughes, C. and Tobin, T. 2015. Morte súbita por rupture da aorta em cavalos, literatura, estudos de casos relatados e fatores de risco. Braz. J. Vet. Res. Anim. Sci. 52: 298-309.

2. Halushka, M. K., Angelini, A., Bartoloni, G., Basso, C., Batoroeva, L., Bruneval, P., Buja, L. M., Butany, J., d’Amati, G., Fallon, J. T., Gallagher, P. J., Gittenberger-de Groot, A. C., Gouveia, R. H., Kholova, I., Kelly, K. L., Leone, O., Litovsky, S. H., Maleszewski, J. J., Miller, D. V., Mitchell, R. N., Preston, S. D., Pucci, A., Radio, S. J., Rodriguez, E. R., Sheppard, M. N., Stone, J. R., Suvarna, S. K., Tan, C. D., Thiene, G., Veinot, J. P. and van der Wal, A. C. 2016. Consensus statement on surgical pathology of the aorta from the Society for Cardiovascular Pathology and the Association For European Cardiovascular Pathology: II. Noninflammatory degenerative diseases - nomenclature and diagnostic criteria. Cardiovasc. Pathol. 25: 247-257. [Medline] [CrossRef]

3. Hatazoe, T., Nakanishi, S., Kimura, Y. and Misumi, K. 2012. Causes of death in Japanese Thoroughbred stallions. J. Jpn. Vet. Med. Assoc. 65: $511-515$.

4. Hickson, S. S., Butlin, M., Graves, M., Taviani, V., Avolio, A. P., McEniery, C. M. and Wilkinson, I. B. 2010. The relationship of age with regional aortic stiffness and diameter. JACC Cardiovasc. Imaging 3: 1247-1255. [Medline] [CrossRef]

5. Imaizumi, K., Nakamura, T., Kiryu, K., Kanemaru, T. and Kaneko, M. 1989. Morphological changes of the aorta and pulmonary artery in thoroughbred racehorses. J. Comp. Pathol. 101: 1-9. [Medline] [CrossRef]

6. Mitchell, G. F., Conlin, P. R., Dunlap, M. E., Lacourcière, Y., Arnold, J. M. O., Ogilvie, R. I., Neutel, J., Izzo, J. L. Jr. and Pfeffer, M. A. 2008. Aortic diameter, wall stiffness, and wave reflection in systolic hypertension. Hypertension 51: 105-111. [Medline] [CrossRef]

7. Parry, B. W., McCarthy, M. A. and Anderson, G. A. 1984. Survey of resting blood pressure values in clinically normal horses. Equine Vet. J. 16: 53-58. [Medline] [CrossRef]

8. Pezet, M., Jacob, M. P., Escoubet, B., Gheduzzi, D., Tillet, E., Perret, P., Huber, P., Quaglino, D., Vranckx, R., Li, D. Y., Starcher, B., Boyle, W. A., Mecham, R. P. and Faury, G. 2008. Elastin haploinsufficiency induces alternative aging processes in the aorta. Rejuvenation Res. 11: 97-112. [Medline] [CrossRef]

9. Ploeg, M., Saey, V., Delesalle, C., Gröne, A., Ducatelle, R., de Bruijn, M., Back, W., van Weeren, P. R., van Loon, G. and Chiers, K. 2015. Thoracic aortic rupture and aortopulmonary fistulation in the Friesian horse: histomorphologic characterization. Vet. Pathol. 52: 152-159. [Medline] [CrossRef]

10. Popescu, M. R., Zugun, F. E., Cojocaru, E., Tocan, L., Folescu, R. and Zamfir, C. L. 2013. Morphometric study of aortic wall parameters evolution 
in newborn and child. Rom. J. Morphol. Embryol. 54: 399-404. [Medline]

11. Rangan, G. K. and Tesch, G. H. 2007. Quantification of renal pathology by image analysis. Nephrology (Carlton) 12: 553-558. [Medline] [CrossRef]

12. Repová-Bednárová, K., Aziriová, S., Hrenák, J., Krajčírovičová, K., Adamcová, M., Paulis, L. and Simko, F. 2013. Effect of captopril and melatonin on fibrotic rebuilding of the aorta in 24 hour light-induced hypertension. Physiol. Res. 62 Suppl 1: S135-S141. [Medline]

13. Robinson, W. F. and Robinson, N. A. 2016. Cardiovascular System pp. 1-101. In: Jubb, Kennedy \& Palmer's Pathology of Domestic Animals: vol. 3, 6th ed. (M. Grant Maxie ed.), Saunders, Philadelphia.

14. Rooney, J. R., Prickett, M. E. and Crowe, M. W. 1967. Aortic ring rupture in stallions. Pathol. Vet. 4: 268-274. [Medline]

15. Saey, V., Ploeg, M., Delesalle, C., van Loon, G., Gröne, A., Ducatelle, R., Duchateau, L. and Chiers, K. 2016. Morphometric properties of the thoracic aorta of warmblood and Friesian horses with and without aortic rupture. J. Comp. Pathol. 154: 225-230. [Medline] [CrossRef]

16. Saey, V., Famaey, N., Smoljkic, M., Claeys, E., van Loon, G., Ducatelle, R., Ploeg, M., Delesalle, C., Gröne, A., Duchateau, L. and Chiers, K. 2015. Biomechanical and biochemical properties of the thoracic aorta in warmblood horses, Friesian horses, and Friesians with aortic rupture. BMC Vet. Res. 11: 285. [Medline] [CrossRef]

17. Sato, F., Shimada, T., Kitamura, H., Campbell, G. R. and Ogata, J. 1994. Changes in morphology of elastin fibers during development of the tunica intima of monkey aorta. Heart Vessels 9: 140-147. [Medline] [CrossRef]

18. Schlatmann, T. J. M. and Becker, A. E. 1977. Histologic changes in the normal aging aorta: implications for dissecting aortic aneurysm. Am. J. Cardiol. 39: 13-20. [Medline] [CrossRef]

19. Shirai, W., Momotani, E., Sato, T., Kashima, T., Saito, T. and Itoi, Y. 1999. Dissecting aortic aneurysm in a horse. J. Comp. Pathol. 120: $307-311$. [Medline] [CrossRef]

20. Sleeper, M. M., Durando, M. M., Miller, M., Habecker, P. L. and Reef, V. B. 2001. Aortic root disease in four horses. J. Am. Vet. Med. Assoc. 219: 491-496, 459. [Medline] [CrossRef]

21. van der Linde-Sipman, J. S., Kroneman, J., Meulenaar, H. and Vos, J. H. 1985. Necrosis and rupture of the aorta and pulmonary trunk in four horses. Vet. Pathol. 22: 51-53. [Medline] [CrossRef]

22. Virmani, R., Avolio, A. P., Mergner, W. J., Robinowitz, M., Herderick, E. E., Cornhill, J. F., Guo, S. Y., Liu, T. H., Ou, D. Y. and O’Rourke, M. 1991. Effect of aging on aortic morphology in populations with high and low prevalence of hypertension and atherosclerosis. Comparison between occidental and Chinese communities. Am. J. Pathol. 139: 1119-1129. [Medline]

23. Wallace, K. D., Selcer, B. A., Tyler, D. E. and Brown, J. 1989. In vitro ultrasonographic appearance of the normal and verminous equine aorta, cranial mesenteric artery, and its branches. Am. J. Vet. Res. 50: 1774-1778. [Medline] 